\title{
Linear scleroderma associated with ptosis and motility disorders
}

Orbital Centre,

Department of

Ophthalmology,

Academic Medical

Centre, Amsterdam, The Netherlands

M S A Suttorp-Schulten L Koornneef

Correspondence to:

M S A Suttorp-Schulten, MD, Department of

Ophthalmology, Academisch

Medisch Centrum,

Meibergdreef $9,1105 \mathrm{Az}$

Amsterdam, The

Netherlands.

Accepted for publication

7 June 1990

\author{
Maria S A Suttorp-Schulten, Leo Koornneef
}

\begin{abstract}
A case is reported in which an 11-year-old girl developed progressive ptosis and a subsequent motility disorder of the right eye. The diagnosis linear scleroderma en coup de sabre was established. Atrophy of the upper levator palpebral and superior rectus muscle could be shown on CT scan.
\end{abstract}

Linear scleroderma is an uncommon dermatological disorder. It produces a unilateral bandlike linear atrophy of the skin and its underlying structures. If it involves the frontoparietal region it is called 'scleroderma en coup de sabre'. '

Sometimes symptoms are so prominent that the patient presents to an ophthalmologist long before the dermatological diagnosis has been established, as happened in our case.

\section{Case report}

The patient, a girl born in 1971, was seen elsewhere at the age of 11 years because of a slowly progressive ptosis of the right eye. The skin above the right eye showed a small linear area of induration and on the right half of the scalp there was a small area of alopecia. She underwent a right levator muscle resection. Two years later she was referred to our clinic because of recurrence of the ptosis. Her visual acuity was $20 / 20$ in both eyes. The motility of both eyes was full. Ophthalmological examination revealed no abnormalities. There was a $6 \mathrm{~mm}$ ptosis of the right eye. A linear lesion of atrophic skin ran from the right forehead down to the upper eyelid with associated loss of hair of the eyebrow and cilia. On the right frontal area of the scalp there

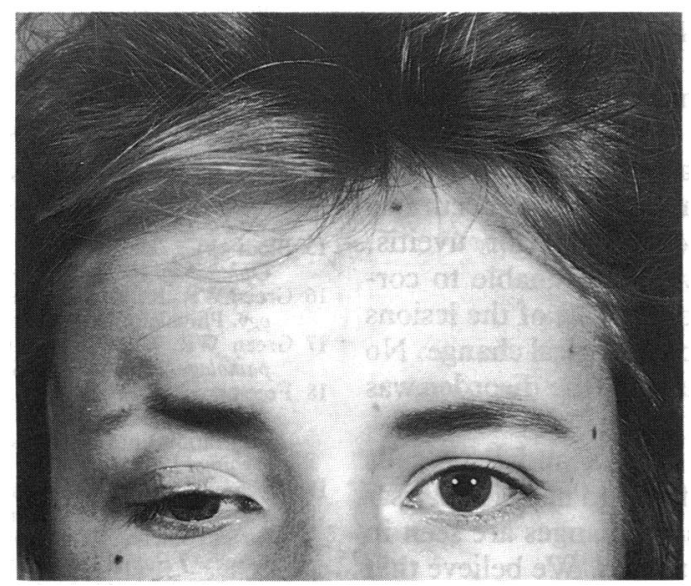

Figure 1 Restriction of elevation of the right eye, atrophic skin, and loss of hair of the right eyebrow. was a linear band of alopecia associated with skin atrophy and underlying bone atrophy. Again a resection of the right palpebral levator muscle was performed.

In 1987 the patient, now aged 16, again presented with another recurrence. At that time she complained of diplopia. There was a restriction of elevation and abduction of the right eye (Fig 1). A progressive myopathy was suspected but no neurological disease could be detected except for denervation of the superior levator palpebral muscle. Myasthenia gravis could be excluded. A CT scan of the orbit revealed a marked atrophy of the levator and rectus superior muscles (Fig 2). Because of the typical skin lesions, which showed progression, the patient was referred to a dermatologist, who established the diagnosis of scleroderma en coup de sabre.

\section{Discussion}

Scleroderma may occur as a systemic disease or as a localised form. The latter presents in three clinical forms: generalised, morphoea, and linear. The linear form may involve the frontoparietal region and is then called coup de sabre. It is a bandlike lesion of induration and atrophy of the skin and its underlying structures.' Involvement of the orbit and the eye is possible but uncommon and has not often been described, especially in ophthalmological literature. Ocular findings include corneal changes such as keratitis ${ }^{3}$ diminished corneal sensibility, ${ }^{4}$ keratitic precipitates, ${ }^{5-7}$ iris changes such as heterochromia ${ }^{89}$ sectoral atrophy, ${ }^{710}$ and mydriasis

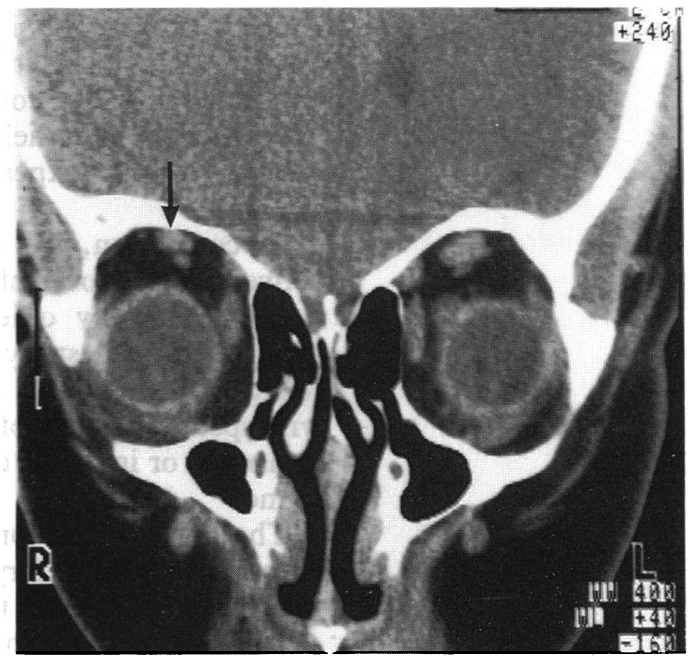

Figure 2: Atrophy of the levator and superior rectus muscles of the right eye on coronal CT scan (arrow). 
without atrophy." Spontaneous filtration ${ }^{+}$and asymmetric pigmentary glaucoma' have been described, and central vein occlusion may also occur. ${ }^{12}$ Atrophy of the skin in the periorbital region results in abnormality of the shape of the eyelid and loss of hair of the eyebrow and cilia. ${ }^{47913}$ Motility disturbances have also been reported, ${ }^{4914}$ and two of these were accompanied by involvement of the levator muscle, resulting in ptosis. ${ }^{914} \mathrm{CT}$ scanning of the orbit has been described in two cases, but no muscle involvement was found. ${ }^{714}$

To our knowledge our case is the first one described in which muscle involvement is demonstrated by CT-scanning. Surgical correction of ptosis has been performed on one patient, with a recurrence of the ptosis after 12 years. In our case the ptosis recurred twice, about two years after surgical correction. An explanation for the recurrence could be that scleroderma en coup de sabre which has its onset during childhood, progresses slowly. ${ }^{15}$

This case illustrates that if ptosis recurs after surgical correction, especially when it is accompanied by skin lesions or motility disturbances, one should consider the diagnosis scleroderma en coup de sabre.
1 Fitzpatrick TB, Eisen AZ, Wolff K, Freedberg IM, Austen KE, eds. Dermatology in general medicine. New York. KE, eds. Dermatology in gen
McGraw-Hill, 1987: 1841-52.

2 Duke-Elder S, MacFaul PA. System of ophthalmology. London: Kimpton, 1974: 13: 330-4.

3 Coyle EF. Scleroderma of the cornea. Br $\mathcal{F}$ Ophthalmol 1956; 40: $239-41$.

4 Gerke E, Meyer-Schwickerath G, Joussen F. Sclerodermie en coup de sabre mit spontaner Filterkissenbildung. Klin Monatsbl Augenheilkd 1976; 168: 426-8.

5 Franceschetti A, Jadassohn W, Paillard R, Hofer R, Golay M. Hémiatrophie faciale ou sclérodermie en coup de sabre. Dermatologica 1958; 116: 331.

6 Sugar HS, Banks TL. Fuchs heterochromic cyclitis associated with facial hemiatrophy (scleroderma en coup de sabre). Am f Ophthalmol 1964; 57: 627-32.

7 Serup J, Alsbirk PH. Localized scleroderma en coup de sabre and iridopalpebral atrophy at the same line. Acta Derm Venereol (Stockh) 1983; 106: 75-7.

8 Perkins ES. Heterochromic uveitis. Trans Ophthalmol Soc UK $1961 ; 81: 53-66$.

9 Stone RA, Schei HG. Periorbital scleroderma associated with heterochromia iridis. Am f Ophthalmol 1980; 90: 858-61.

10 Segal P, Jablonska S, Mrzyglod S. Ocular changes in linear scleroderma. Am F Ophthalmol 1961; 51: 807-13.

11 Tang RA, Mewis-Christmann L, Wolf J, Wilkin RB. Pseudo oculomotor palsy as the presenting sign of linear scleroderma. f Pediatr Ophthalmol Strabismus 1986; 23: 236-8.

12 Josten K. Sclerodermie en coup de sabre und Auge. Klin Monatsbl Augenheilkd 1958; 133: 567-70.

13 Olver J, Laidler P. Acquired Brown's syndrome in a patien with combined lichen sclerosus at atrophicus and morphoea. Brf Ophthalmol 1988; 72: 552-7.

14 Serup J, Serup L, Sjo O. Localized scleroderma 'en coup de sabre' with external eye muscle involvement at the same line. Clin Exp Dermatol 1984; 9: 196-200.

15 Curtis AC, Jansen TG. The prognosis of localized scleroderma. Arch Dermatol 1958; 78: 749-56. 